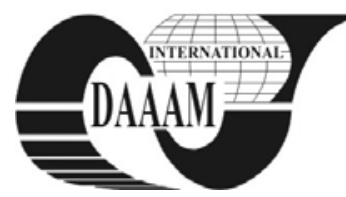

Annals of DAAAM for 2011 \& Proceedings of the 22nd International DAAAM Symposium, Volume 22, No. 1, ISSN 1726-9679 ISBN 978-3-901509-83-4, Editor B. Katalinic, Published by DAAAM International, Vienna, Austria, EU, 2011 Make Harmony between Technology and Nature, and Your Mind will Fly Free as a Bird Annals \& Proceedings of DAAAM International 2011

\title{
QUANTIFIED RESULTS OF RAPID COOLED C-PATTERN IN AGITATED QUENCHANT
}

\author{
DUEHRING, S[teven]; SPANIELKA, J[an] \& TARABA, B[ohumil]
}

\begin{abstract}
The article is focused on the issue of heat treatment. The cooling curves were obtained for Isorapid 277HM with an experimental way of temperature measuring and their statistical processing. Material data of the material pattern $50 \mathrm{CrMo} 4$ were obtained from the Material Data Sheet (MDS) of Deutsche Edelstahlwerke (***, 2011). The cooling oil

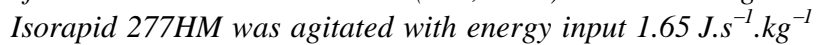
and had a constant temperature of $50^{\circ} \mathrm{C}$. In the follow of this article were showed the experimentally obtained results: geometry distortion, dimensional and metallurgical evaluation. Key words: heat treatment, Isorapid 277HM, agitated oil, Cpattern, steel 50CrMo4, distortion
\end{abstract}

\section{INTRODUCTION}

Today a typical problem is the exact and reliable prediction of distortion and failures in the heat treatment processes. Beside the possibilities of experimental, analytical and semi-empirical methods will used the numerical procedures increasingly. The experimental methods with prototypes are very expensive and need a lot of time. Often these methods can not used in practise, reasoned by very complicated conditions, difficult geometrics and the non-exactly reproducibility. But basic data's are determined from experiments. FEM simulations are only convincing with regard to well-known and defined boundary conditions.

The kind of quenching medium, the selection of quenching medium temperature, the selection of the medium state (no agitated, agitated), the material properties at start (e.g. manufacturing process, follow up treatment) and the changes of material behaviour are determining factors. Basically for application in a numerical simulation is the quantitative definition of the pattern surface and the material properties. In summary the experiment will give basic information for detecting of room for improvement of simulation.

\section{EXPERIMENTAL SETUP AND PROCEDURE}

The experimental setup consists of an electrical resistance furnace of LM 212.10 type, a "C"-pattern of 50CrMo4; oil Isorapid 277HM - agitated, with mass of $28 \mathrm{~kg}$ and pneumatically manipulator for pattern moving. The outer diameter (OD) of the pattern was $110 \mathrm{~mm}$, the inner diameter (ID) was $68 \mathrm{~mm}$ and its high $20 \mathrm{~mm}$ see Fig.1.
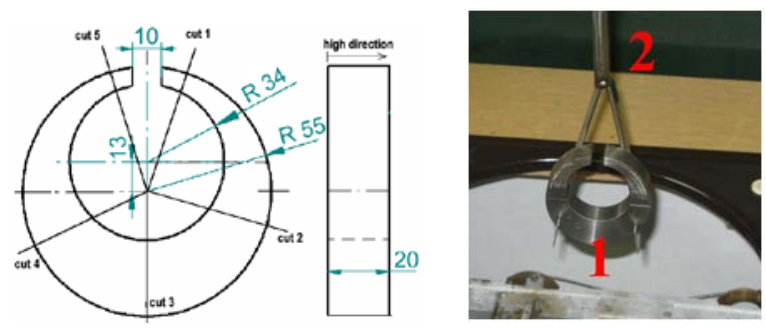

Fig. 1. Measured size and photo of pattern in holder
The material of the pattern is 50CrMo4 (1.7228) and its properties see $(* * *, 2011$, Szmolka, Hazlinger, 2009). At the beginning of the experiment the pattern was heated up from room temperature to the initial temperature $850^{\circ} \mathrm{C} \pm 5^{\circ} \mathrm{C}$. Reference of the temperature of the pattern was the furnace temperature control. The oil temperature was $50^{\circ} \mathrm{C}$ checked by thermometer immersed in the cooling medium and will accept as constant in the oil tank. The quenching oil was agitated with energy input $1.65 \mathrm{~J} . \mathrm{s}^{-1} \cdot \mathrm{kg}^{-1}$ (Hajdu\&Taraba, 2010). If the pattern has reached the target temperature in the furnace, the pneumatic manipulator moves the pattern as quick as possible into the cooling medium. The pattern was kept in the oil more then $20 \mathrm{~min}$ to be sure, that the pattern has reached the oil temperature also in the core. Afterwards the pattern was analyzed with regard to the geometrical dimension, hardness distribution and microstructure.

\section{OBTAINED RESULTS OF THE EXPERIMENT}

After removing the pattern, the figure 2 shows the pattern in original with definition of measurement points. On the surface is observed visually black spots which are not hard bonded to the rest of material and comes from free sooty particles. The pattern was stored for 7 days. For the dimensional evaluation the pattern is measured with a $\mathrm{CMM}$ at $20.01{ }^{\circ} \mathrm{C}$ with an accuracy of $2 \mu \mathrm{m}$, results see in Table 1 .

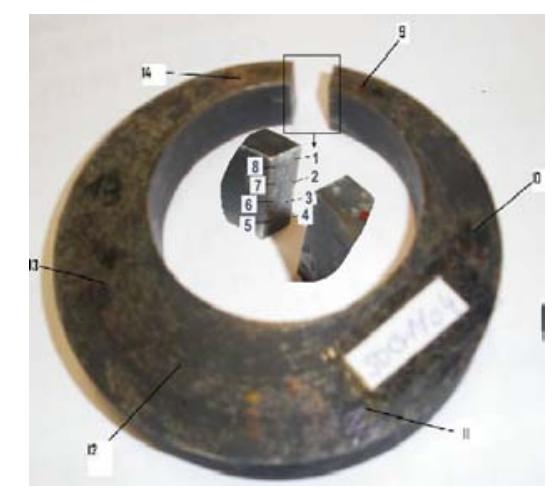

Fig. 2. Pattern after quenching with defined measurement points

\begin{tabular}{|c|l|c|c|c|c|}
\hline No & description & $\begin{array}{c}\text { value } \\
{[\mathrm{mm}]}\end{array}$ & No & $\begin{array}{c}\text { description } \\
{[\mathrm{mm}]}\end{array}$ & $\begin{array}{c}\text { value } \\
{[\mathrm{mm}]}\end{array}$ \\
\hline 1 & Clear width & 10.607 & 11 & $\begin{array}{c}\text { Probe } \\
\text { depth }\end{array}$ & 20.216 \\
\hline 2 & Clear width & 10.619 & 12 & $\begin{array}{c}\text { Pattern } \\
\text { depth }\end{array}$ & 20.231 \\
\hline 3 & Clear width & 10.669 & 13 & $\begin{array}{c}\text { Pattern } \\
\text { depth }\end{array}$ & 20.091 \\
\hline 4 & Clear width & 10.671 & 14 & $\begin{array}{c}\text { Pattern } \\
\text { depth }\end{array}$ & 19.949 \\
\hline 5 & Clear width & 10.428 & 15 & $\begin{array}{c}\text { ID depth } \\
2.5\end{array}$ & 68.258 \\
\hline
\end{tabular}




\begin{tabular}{|c|c|c|c|c|c|}
\hline 6 & Clear width & 10.307 & 16 & $\begin{array}{c}\text { ID depth } \\
10.0\end{array}$ & 68.239 \\
\hline 7 & Clear width & 10.303 & 17 & $\begin{array}{c}\text { ID depth } \\
17.5\end{array}$ & 68.177 \\
\hline 8 & Clear width & 10.437 & 18 & $\begin{array}{c}\text { OD depth } \\
2.5\end{array}$ & 110.210 \\
\hline 9 & $\begin{array}{c}\text { Pattern } \\
\text { depth }\end{array}$ & 19.954 & 19 & $\begin{array}{c}\text { OD depth } \\
10.0\end{array}$ & 110.194 \\
\hline 10 & $\begin{array}{c}\text { Pattern } \\
\text { depth }\end{array}$ & 20.075 & 20 & $\begin{array}{c}\text { OD depth } \\
17.5\end{array}$ & 110.184 \\
\hline
\end{tabular}

Tab. 1. Dimensional values from CMM regarding to defined measurement points

For visualization of distortion it was taken a contour determination of ID and OD in different depths of $2.5 \mathrm{~mm}$, $10.0 \mathrm{~mm}$ and $17.5 \mathrm{~mm}$ with a 3D - surface scanning procedure with CMM, see exemplary figure $3,4 \rightarrow$ bold black line is the original edge of body after, middle circle is before .

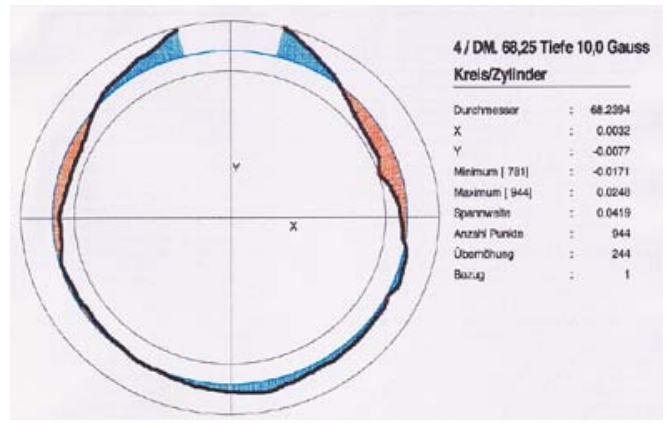

Fig. 3. Distortion ID at high $10 \mathrm{~mm}$

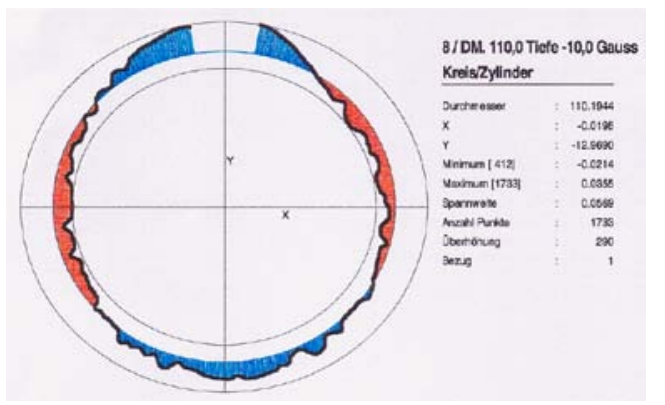

Fig. 4. Distortion OD at high $10 \mathrm{~mm}$

The figure 5 shows the absolute range in $\mathrm{mm}$ of distortion of Table 1.

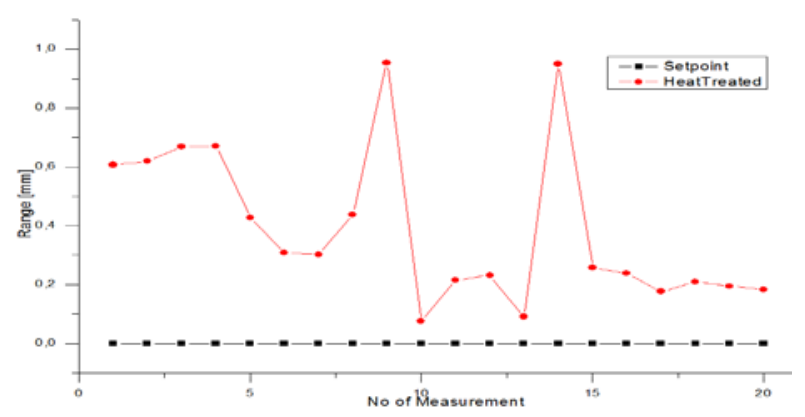

Fig. 5. Absolute range of distortion

\begin{tabular}{|c|c|c|c|c|c|}
\hline & cut 1 & cut 2 & cut 3 & cut 4 & cut 5 \\
\hline core [HV1] & 730 & 779 & 763 & 745 & 751 \\
\hline edge [HV1] & 745 & 748 & 763 & 748 & 763 \\
\hline
\end{tabular}

Tab. 2. Hardness values after heat treatment

The evaluation of hardness regarding to cut systematic obtains the following results in table 2 and metallurgical investigation see in figure 6 . For metallurgical evaluation see figure 6 we can summarize a finer grain size in edge area. Micro- and makro cracks were not detected. The residual austenite content in border structure is lower than $<20 \%$. Ferrite content is lower than $3 \%$ and ferrite-pearlite, fine grained with even distribution were not detected. Martensite and Bainite is detected in the core, a result of lower cooling speed in core.

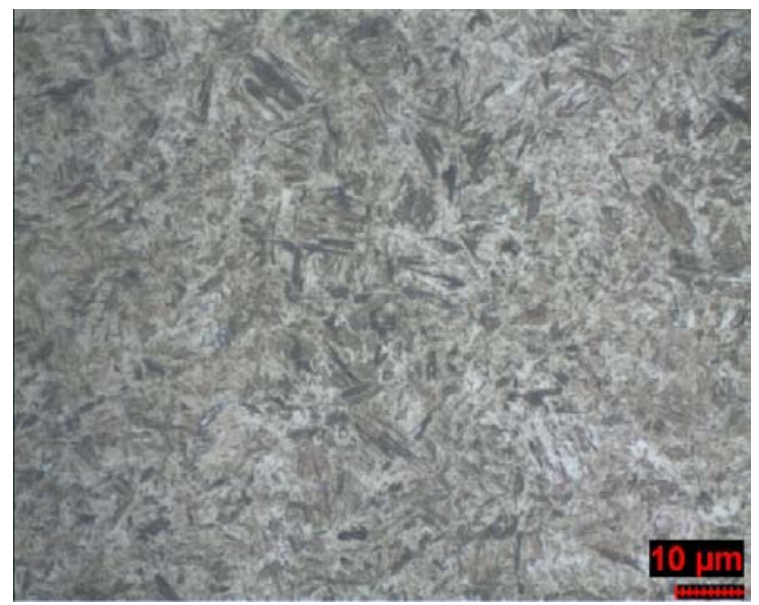

Fig. 6. Metallurgical investigation core

\section{CONCLUSION}

The elastic deformation part is following the Hook's Law, the thermal deformation part will summarized of the thermal expansions of the structural constituents. For the calculation of transformation into martensite during the rapid cooling we use the CCT or the Koistinen-Marburger approach (***, 2011). The outcome of this is the part of plastic dilatation. In order to calculate the plastic transformation part of expansion we need the flow criteria, the flow law and a formula which consider the increments of deformation linked with the current strains with regard to current temperature. Furthermore we have to respect creeping effects, evaluation of quenching power, effect of process variables (bath temperature, agitation and others) on cooling behaviour, effect of cooling characteristics on residual stress and distortion. The real result of the experiment will used for comparison and improvement within simulation approaches.

\section{ACKNOWLEDGEMENTS}

Thank to MTF STU Bratislava for facilitating implementation of research. Article was supported by VEGA 1/1041/11.

\section{REFERENCES}

*** (2011) http://www.dew-stahl.com/fileadmin/files/dewstahl.com/documents/Publikationen/Werkstoffdatenblaetter/ Baustahl/1.7228_de.pdf, Accessed 2011-06-05

*** (2011) http://www.petrofer.com.ua/content/hardening_com pound/ 2_1.htm, Accessed 2011-06-05

Hajdu Š., Taraba B. (2010). The numerical approach to the calculation of combined heat transfer coefficient for cooling probe immersed in agitated quenching oil. In: Annals of DAAAM and Proceedings of DAAAM Symposium. - ISSN 1726-9679. - Vol. 21, No 1. Vienna, 2010. - ISBN 978-3901509-73-5, s. $1141-1142$

Szmolka T., Hazlinger M. (2009). Influence of tempering temperature on fracture behaviour of 50CrMo4 steel. In: 8th Youth Symposium on Experimental Solid Mechanics. Györ, Hungary. Scientific Society of Mechanical Engineers, 2009. - ISBN 978-963-9058-26-2. - S. 84-85

*** (2011) http://www.math.uni bremen.de/zetem/cms/media.php/262/report0702.pdf 